\title{
Tranexamic Acid and Ethamsylate for Reducing Blood Loss in Patient Undergoing Lower Segment Cesarean Section at High Risk for Post-Partum Hemorrhage: A Pilot Study
}

\author{
Ahmed Alanwar*, Sherif Akl, Sherif El-Mekawi, Marwan M. Gamal \\ Ain Shams Maternity Hospital, Faculty of Medicine, Ain Shams University, Cairo, Egypt \\ Email: *eladwar@hotmail.com
}

How to cite this paper: Alanwar, A., Akl, S., El-Mekawi, S. and Gamal, M.M. (2020) Tranexamic Acid and Ethamsylate for Reducing Blood Loss in Patient Undergoing Lower Segment Cesarean Section at High Risk for Post-Partum Hemorrhage: A Pilot Study. Open Journal of Obstetrics and Gynecology, 10, 1340-1350.

https://doi.org/10.4236/ojog.2020.1090123

Received: September 3, 2020

Accepted: September 21, 2020

Published: September 24, 2020

Copyright $\odot 2020$ by author(s) and Scientific Research Publishing Inc. This work is licensed under the Creative Commons Attribution International License (CC BY 4.0).

http://creativecommons.org/licenses/by/4.0/ (c) (i) Open Access

\begin{abstract}
Objective: To assess the efficacy of intravenous tranexamic acid and ethamsylate in reducing blood loss during and after elective lower segment cesarean delivery in patients at high risk for postpartum hemorrhage. Methods: A double-blind, randomized placebo-controlled study was undertaken of women undergoing elective lower-segment cesarean delivery of a full-term pregnancy at high risk for postpartum hemorrhage at Ain Sham University Maternity Hospital in Cairo, Egypt, between January 2019 and October 2019. Patients were randomly assigned (1:1) using computer-generated random numbers to receive either $1 \mathrm{~g}$ tranexamic acid and $1 \mathrm{gm}$ ethamsylate or $5 \%$ glucose (placebo) just after delivery of the fetus. Prophylactic oxytocin was administered to all women. Preoperative and postoperative complete blood count, hematocrit values, and maternal weight were used to calculate the estimated blood loss (EBL) during the cesarean, which was the primary outcome. Results: Analyses included 32 women in each group. Our results showed that tranexamic acid and ethamsylate significantly reduced bleeding during and after cesarean delivery. The study group's total blood loss (149.22 $\pm 54.74 \mathrm{ml})$ was significantly less than the control group $(353.75 \pm 115.56 \mathrm{ml})$ $(\mathrm{p}<0.001)$. In our study, postoperative hemoglobin and hematocrit were significantly higher in the study group than the control group ( $\mathrm{p}<0.001)$; Reduction in hemoglobin and hematocrit were significantly less in the study group than the control group $(\mathrm{p}<0.001)$. Conclusion: The use of tranexamic acid and ethamsylate during cesarean delivery can significantly reduce blood loss during and after cesarean delivery.
\end{abstract}

\section{Keywords}

Blood Loss, Postpartum Hemorrhage, Elective Cesarean Delivery, Tranexamic 
Acid, Ethamsylate

\section{Background}

Worldwide $15 \%$ of deliveries are done by cesarean [1]. Although cesarean delivery is planned to be a lifesaving procedure, diminishing both maternal and fetal morbidity and mortality [2], blood loss during cesarean is double that of vaginal delivery [3]. Postpartum hemorrhage ( $\mathrm{PPH}$ ) remains the main cause of maternal mortality and accounts for about one-fourth of all maternal deaths worldwide. Its risk factors include previous $\mathrm{PPH}$, multiple pregnancies, polyhydramnios, and macrosomia [4]. Most of these could be avoided through the use of prophylactic uterotonics by timely and appropriate management [5]. Therefore, medications such as oxytocin, ergometrine, prostaglandin F2 $\alpha$, and misoprostol (prostaglandin E1) are commonly used to minimize intraoperative and postoperative blood loss during cesarean delivery [6] [7]. In addition to this enhancement of chemical hemostasis, a complementary biochemical hemostatic effect might be expected from the complementary use of prohemostatic drugs as tranexamic acid or ethamsylate [8].

Tranexamic acid (TXA) is a synthetic derivative of the amino acid lysine that exerts its antifibrinolytic action through the reversible block of the lysine binding sites on plasminogen molecules. Intravenous administration of TXA has been routinely used for treating and preventing bleeding with good results [9]. During delivery, when the placenta separates from the uterine wall, sequential physiologic and hemostatic changes occur and decrease bleeding, including strong myometrial contraction, increased platelet activation, and a massive release of coagulant factors; at the same time, however, fibrinolytic activity increases [10]. While oxytocin administration facilitates the first mechanism, tranexamic acid administration might be able to counter the latter and thus enhances the hemostatic process [11]. Prophylactic TXA given before cesarean skin incision in women undergoing cesarean delivery, significantly decreases blood loss, including postpartum hemorrhage and severe postpartum hemorrhage, in addition to the standard prophylactic oxytocin given after delivery of the neonate [12]. So prophylactic TXA administration is effective and safe for postpartum hemorrhage prevention [13].

Ethamsylate is a synthetic hemostatic drug indicated in cases of capillary bleeding. It exerts a hemostatic effect by acting on the first step of hemostasis by improving platelet adhesiveness and restoring capillary resistance. It decreases bleeding time and enhances platelet aggregation. It reduces capillary bleeding when platelets are adequate. The drug exerts antihyaluronidase action and improves capillary wall stability. It inhibits PGI-2 synthesis and correct abnormal platelet function. Side effects include rash, headache, nausea, and fall in blood pressure only after intravenous administration [14]. 
The aim of the present study was to evaluate the efficacy and safety of intravenous tranexamic acid and ethamsylate in reducing blood loss during and after elective lower segment cesarean delivery in patients at high risk for postpartum hemorrhage.

\section{Material and Methods}

This was a prospective double-blind randomized controlled clinical trial study conducted at Ain Shams University Maternity Hospital, Cairo, Egypt from January 2019 to October 2019. It is registered under NCT02604719 on clinicaltrials.gov. 64 women at 38 - 40 weeks of gestation at high risk for postpartum hemorrhage (having one or more risk factors for $\mathrm{PPH}$ e.g. previous history of $\mathrm{PPH}$, multiple pregnancy, obesity [BMI $>30$ ], polyhydramnios [AFI $>25 \mathrm{~cm}$ ], macrosomic baby [weight $>4.5 \mathrm{~kg}$ ]) and planned for elective delivery by lower segment caesarean section were eligible for inclusion in the study (the indication was repeat cesarean delivery). Exclusion criteria included history of venous thrombosis (e.g. DVT) or arterial thrombosis (e.g. myocardial infarction or stroke), maternal medical disorders (e.g. cardiac, renal, and hepatic diseases, or coagulopathies), abnormal placentation (e.g. placenta previa, morbidly adherent placenta or abruptio placenta) or known allergy to tranexamic acid or ethamsylate.

Sample size justification: Data from a recent Cochrane systematic review (Hofemyr, 2011) revealed that the risk of post-partum blood loss $>500 \mathrm{ml}$ was $12.38 \%$ (14/113) in women who received Tranexamic acid, in contrast to $29.72 \%$ (33/111) in women who did not. Calculation according to these values produced a minimal sample size of 32 cases per group.

Institutional review and ethical board approval were obtained, and all participants provided informed written consent following a discussion on the nature of the study as well as the expected value, outcome, and possible adverse effects.

On the day of their scheduled surgery, participants were randomly assigned in a 1:1 ratio to receive either intravenous tranexamic acid and ethamsylate or intravenous glucose (placebo) given just after delivery of the fetus during cesarean delivery. Randomization was performed using computer-generated random numbers. Neither the surgeon nor the investigator was aware whether the patient received tranexamic acid and ethamsylate or placebo (double-blinded technique). Placebo was the same in size, color, and shape to the original drug.

A full medical history was obtained from all participants. Obstetric ultrasonography and laboratory tests were performed, including prothrombin time, complete blood count, and liver and kidney function tests. Maternal body weight and vital signs (heart rate, blood pressure) were checked 30 minutes before surgery.

Patients assigned randomly into one of two groups: group 1 (the case group); consisted of 32 patients received 1 gm tranexamic acid (Kapron, Amoun, Egypt) and $1 \mathrm{gm}$ ethamsylate (Dicynone, Memphis, Egypt) diluted in $20 \mathrm{ml}$ of 5\% glucose given intravenous slowly in the 2 minutes after delivery of the fetus. Group 2 (the control group), consisted of 32 patients, received a placebo (20 $\mathrm{ml}$ of 5\% 
glucose) in the 2 minutes after the delivery of the fetus. Following delivery, patients in both groups received the routine prophylaxis intravenous 10 IU Oxytocin (Syntocinon, Novartis, Basel, Switzerland). Summation of blood loss by suckers, towels, and pads placed under women buttocks then weighting the towels and pads to allow objective measurement of blood loss. Vital data (pulse and blood pressure) was monitored postoperatively, complete blood count test was performed 24 hours after delivery.

Each patient in the study was tested for the following endpoints; operative blood loss (measured by suckers, towels, and pads placed under women buttocks just after delivery and weighting the pads and towels to allow objective measurement of blood loss), the need for blood transfusion, pre- and post-operative hemoglobin and hematocrit (peripartum change) and if $\mathrm{PPH}$ occurs, measurement of vaginal blood loss objectively.

Upon discharge, patients who received tranexamic acid were given a brief orientation regarding symptoms and signs of a thromboembolic event and were instructed to contact the investigators if any occurred. All patients were examined for thromboembolic signs at the 1- and 4-week follow-up visits.

Descriptive statistics for measured variables expressed as a range, mean and standard deviation (for metric data); range, median and inter-quartile range (for discrete data); and number and proportions (for categorical data). Data of both groups compared using t-test (for quantitative parametric measures), Mann-Whitney's U-test (for quantitative non-parametric measures) and chi-squared and Fischer's Exact tests (for categorical measures). Pearson's correlation coefficient (for metric variables) and Spearman's correlation coefficient (for rank variables) were used to estimate the association between variables. $\mathrm{P}<0.05$ was considered significant. Statistical analysis performed using Statistical Package for Social Sciences $\left(\right.$ SPSS $^{\circledR}$ ) for Windows ${ }^{\circledR}$ version 16.0. (SPSS Inc. Chicago, IL, USA).

\section{Results}

70 pregnant women were enrolled. Six women were excluded from the study; 3 women with a history of venous thrombosis, 2 women had medical disorders (cardiac and hepatic diseases) and 1 woman had abnormal placentation (morbidly adherent placenta). 64 women were included in the final analysis, divided randomly into two groups; 32 women in the study group (tranexamic acid and ethamsylate) and 32 women in the control group (placebo).

There was no significant difference as regard patient characteristics (age, weight, BMI, and gestational age) between study and control groups [Table 1].

There was a significant difference between two groups as regards postoperative examination (pulse, pads, drains) and need for blood transfusion. The study group's total blood loss: $(149.22 \pm 54.74 \mathrm{ml})$ was significantly less than control group $(353.75 \pm 115.56 \mathrm{ml})(\mathrm{p}<0.001)$ [Table 2; Figure 1].

In our study postoperative hemoglobin was significantly higher in the study group than the control group $(\mathrm{p}<0.001)$; Reduction in Hemoglobin was significantly 
Table 1. Comparison between two groups as regards demographic data (age, BMI, and gestational age).

\begin{tabular}{|c|c|c|c|c|c|}
\hline & $\mathbf{N}$ & Minimum & Maximum & Mean & SD \\
\hline Age (years) & 64 & 21.00 & 32.00 & 27.44 & 3.01 \\
\hline BMI & 64 & 22.20 & 36.20 & 27.74 & 3.70 \\
\hline & & \multicolumn{2}{|c|}{$\mathbf{N}$} & \multicolumn{2}{|c|}{$\%$} \\
\hline \multirow[t]{4}{*}{ Gestational age (weeks) } & 38 & \multicolumn{2}{|c|}{27} & \multicolumn{2}{|c|}{42.2} \\
\hline & 39 & \multicolumn{2}{|c|}{34} & \multicolumn{2}{|c|}{53.1} \\
\hline & 40 & \multicolumn{2}{|c|}{3} & \multicolumn{2}{|c|}{4.7} \\
\hline & Total & \multicolumn{2}{|c|}{64} & \multicolumn{2}{|c|}{100.0} \\
\hline
\end{tabular}

SD: standard deviation; BMI: body mass index.

Table 2. Comparison between two groups regarding post-operative examination and investigations.

\begin{tabular}{|c|c|c|c|c|c|c|c|}
\hline & & \multicolumn{4}{|c|}{ Group } & \multirow{3}{*}{$t^{*}$} & \multirow{3}{*}{$P$ value } \\
\hline & & \multicolumn{2}{|c|}{ Treatment $(\mathrm{N}=32)$} & \multicolumn{2}{|c|}{ Placebo $(\mathrm{N}=32)$} & & \\
\hline & & Mean & SD & Mean & SD & & \\
\hline $\mathrm{Hb}$ & & 10.81 & 0.81 & 9.33 & 0.65 & 8.06 & $<0.001$ \\
\hline $\mathrm{Ht}$ & & 32.42 & 2.43 & 28.10 & 1.98 & 7.79 & $<0.001$ \\
\hline Pulse & & 90.25 & 4.02 & 94.69 & 7.58 & 2.92 & 0.01 \\
\hline \multirow[t]{2}{*}{ Pads } & & 149.22 & 54.74 & 353.75 & 115.56 & 9.05 & $<0.001$ \\
\hline & & $\mathbf{N}$ & $\%$ & $\mathbf{N}$ & $\%$ & \multicolumn{2}{|c|}{ Chi Square test $P$ value } \\
\hline \multirow{2}{*}{ Drain } & yes & 1 & $3.1 \%$ & 4 & $12.5 \%$ & \multirow{2}{*}{$1.95^{* *}$} & \multirow{2}{*}{0.36} \\
\hline & no & 31 & $96.9 \%$ & 28 & $87.5 \%$ & & \\
\hline \multirow{2}{*}{$\begin{array}{l}\text { need for blood } \\
\text { transfusion }\end{array}$} & yes & 0 & $.0 \%$ & 3 & $9.4 \%$ & \multirow{2}{*}{$3.15^{* *}$} & \multirow{2}{*}{0.24} \\
\hline & no & 32 & $100.0 \%$ & 29 & $90.6 \%$ & & \\
\hline
\end{tabular}

${ }^{\star}$ Independent samples t-test; ${ }^{*}$ Fisher exact.

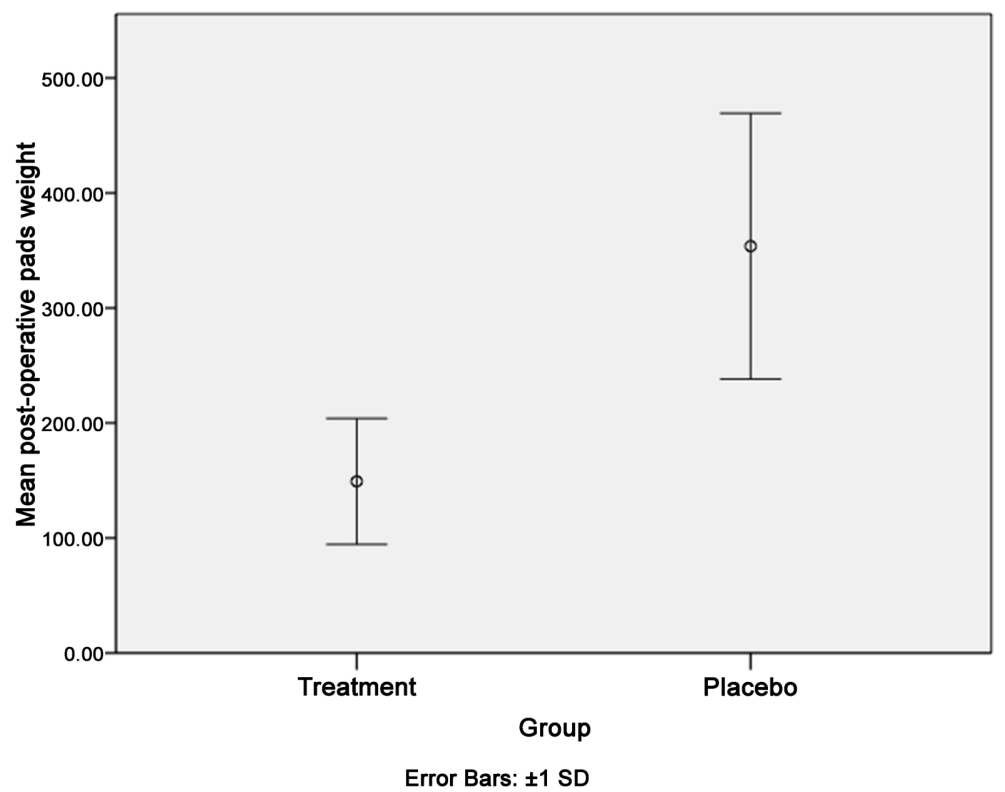

Figure 1. Comparison between two groups regarding post-operative blood loss. 
less in the study group than control group (11 to 10.8 vs 10.7 to 9.3$)(\mathrm{p}<0.001)$ [Table 3; Figure 2]. Also, postoperative hematocrit was significantly higher in study group than control group $(\mathrm{p}<0.001)$ : reduction in hematocrit was significantly less in the study group than in control group (33.2 to 32.4 vs 32.2 to 28.1 ) $(\mathrm{p}<0.001)$ [Table 4; Figure 3].

Table 3. Comparison between two groups regarding change in hemoglobin level (peripartum changes).

\begin{tabular}{cccccccc}
\hline \multirow{2}{*}{ Group } & Hb & Mean & Std. Error & \multicolumn{2}{c}{ 95\% Confidence Interval } & F\# & P value \\
\cline { 5 - 6 } Treatment & Pre & 11.066 & 0.133 & 10.801 & 11.331 & 70.66 & $<0.001$ \\
& Post & 10.806 & 0.130 & 10.546 & 11.066 & & \\
Placebo & Pre & 10.772 & 0.133 & 10.507 & 11.037 & & \\
& Post & 9.325 & 0.130 & 9.065 & 9.585 & \\
\hline
\end{tabular}

\#Repeated measures ANOVA test (Time * group); Hb: hemoglobin.

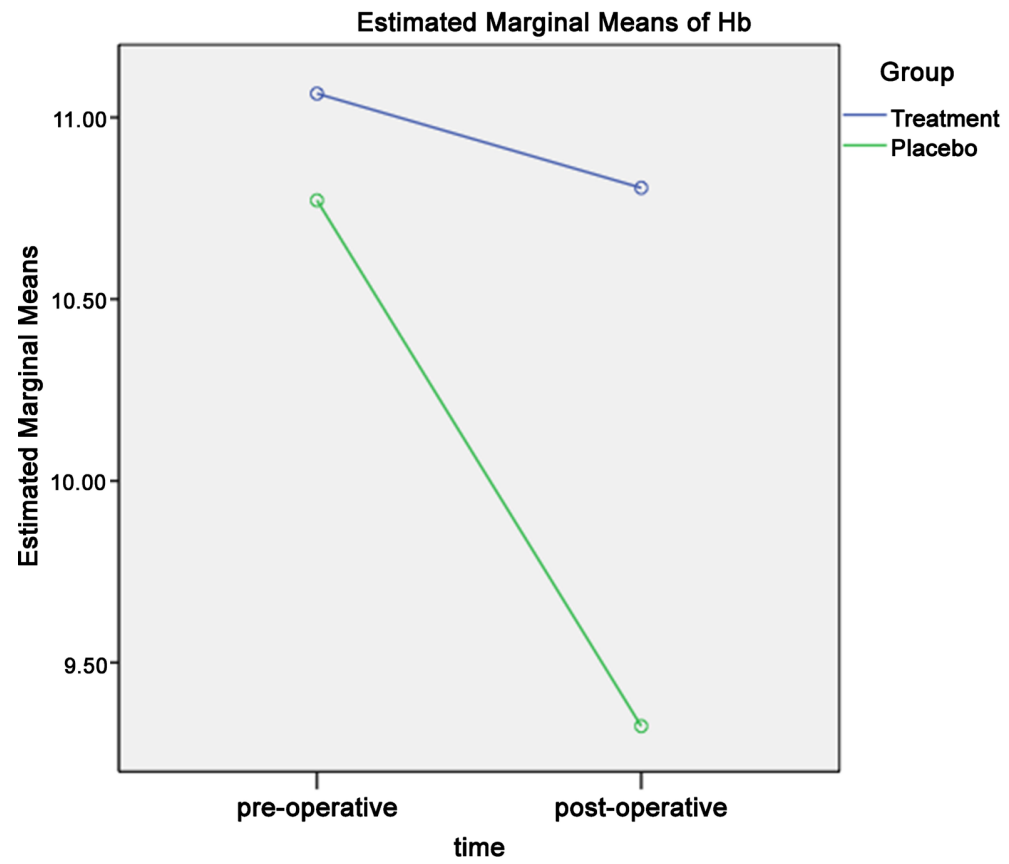

Figure 2. Comparison between two groups regarding change in $\mathrm{Hb}$ level (peripartum changes).

Table 4. Comparison between two groups regarding change in hematocrit level (peripartum changes).

\begin{tabular}{cccccccc}
\hline \multirow{2}{*}{ Group } & Ht & Mean & Std. Error & \multicolumn{2}{c}{ 95\% Confidence Interval } & F\# & P value \\
\cline { 5 - 6 } Treatment & Pre & 33.197 & 0.387 & 32.423 & 33.970 & 57.95 & $<0.001$ \\
& Post & 32.419 & 0.392 & 31.635 & 33.203 & & \\
Placebo & Pre & 32.222 & 0.387 & 31.448 & 32.995 & & \\
& Post & 28.100 & 0.392 & 27.316 & 28.884 & & \\
\hline
\end{tabular}

\#Repeated measures ANOVA test (Time * group); Ht: hematocrit. 


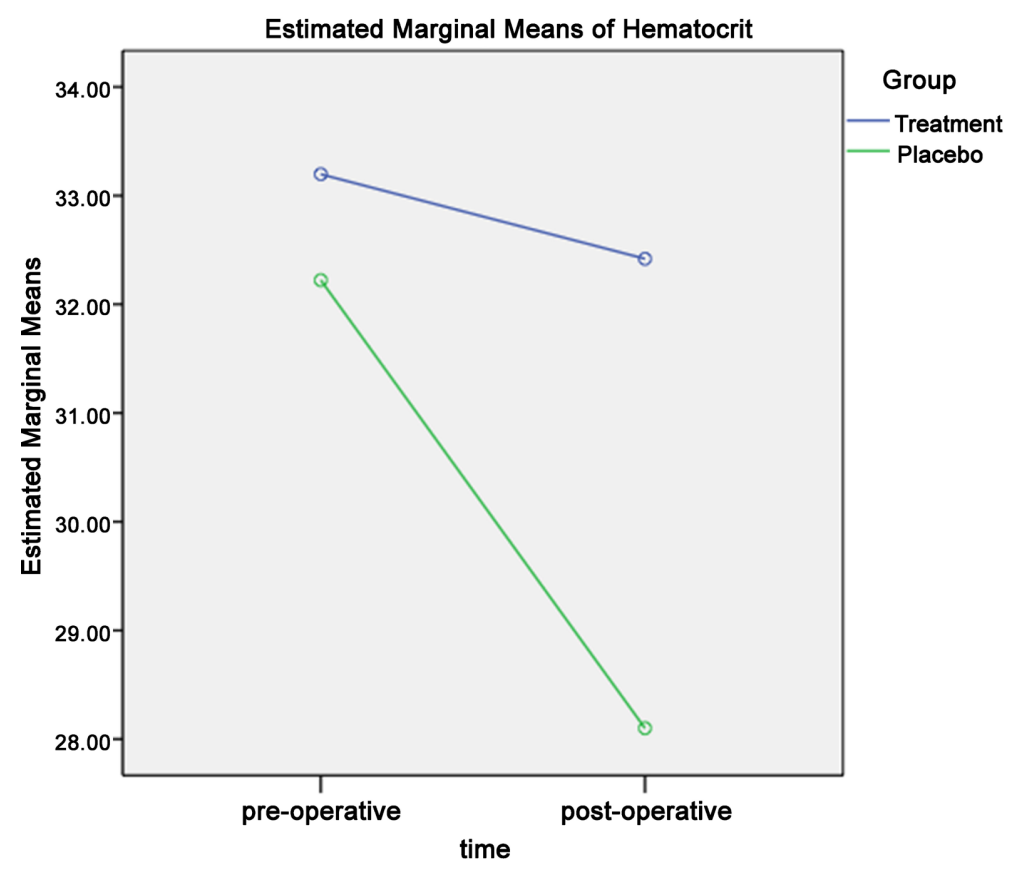

Figure 3. Comparison between two groups regarding change in $\mathrm{Ht}$ level (peripartum changes).

\section{Discussion}

The present study has demonstrated that intraoperative intravenous administration of tranexamic acid together with ethamsylate given just after delivery of the fetus is an effective method for reduction of blood loss during elective lower-segment cesarean delivery. Furthermore, tranexamic acid and ethamsylate reduce the need for ecbolic drugs during the postoperative period and reduces the postpartum blood loss in patients with high risk for postpartum hemorrhage. No adverse effects were reported.

Several previous studies have used tranexamic acid for the control of bleeding associated with cesarean delivery. In the study of Jianjun et al., the study group consisted of 88 women received tranexamic acid, whereas the control group 86 women had not received. Tranexamic acid significantly reduced the quantity of blood from the end of cesarean section to 2 hours postpartum: $(46.6 \pm 42.7 \mathrm{ml})$ in the study group versus $(84.7 \pm 80.2 \mathrm{ml})$ in the control group $(\mathrm{p}<0.01)$, It also significantly reduced the quantity of total blood from placental delivery to 2 hours postpartum: $(379.2 \pm 160.1 \mathrm{ml})$ in the study group versus $(441.7 \pm 189.5$ $\mathrm{ml})$ in the control group $(\mathrm{p}=0.02)$. Mild, transient side effects occurred more often in the tranexamic acid group than in the control group [15]. In the study of Leila Sekhavat et al., the study group consisted of 45 women who received tranexamic acid, whereas the control group 45 women who did not receive. Tranexamic acid significantly reduced the quantity of blood from the end of cesarean section to 2 hours postpartum: $(28.02 \pm 5.53 \mathrm{ml})$ in the study group versus $(37.12 \pm 8.97 \mathrm{ml})$ in the control group $(\mathrm{p}=0.001)$. Hemoglobin 24 hours after cesarean section was significantly greater in the tranexamic group than the 
control group $(12.57+1.33$ in the tranexamic group and $11.74+1.14$ in the control group $(\mathrm{p}=0.002)$. Tranexamic acid was not associated with any side effects or complications [16].

In 2011, the CRASH-2 trial [17] showed that early administration of tranexamic acid significantly decreases mortality in trauma patients with hemorrhage. As a result of this trial, the drug was included in the WHO Model List of Essential Medicines [18]. In obstetric and gynecologic practice, tranexamic acid is most commonly used in the management of pregnancy-associated bleeding (threatened abortion and placenta previa) and idiopathic menorrhagia [9]. Randomized controlled studies have shown that tranexamic acid reduces blood loss during and after cesarean [19] [20], indicating that its use effectively prevents and treats bleeding. Nevertheless, these studies are limited and have small sample sizes compared with those assessing efficacy of tranexamic acid in blood loss reduction during other surgical interventions, also most of these studies were done on low risk patients for postpartum hemorrhage, in contrast to our study which was done on patients with high risk for postpartum hemorrhage.

However, the place of tranexamic acid is still discussed, the results of the WOMAN (World Maternal Antifibrinolytic) trial recently published in the Lancet journal, contribute to strengthening the place of tranexamic acid in postpartum hemorrhage. The WOMAN trial aimed to assess the impact of early administration of tranexamic acid on death and hysterectomy in women experiencing postpartum hemorrhage. Between 2010 and 2016, 20,060 women with a clinical diagnosis of postpartum hemorrhage in 21 low and middle-income countries were included in this randomized double-blind placebo-controlled trial to intravenously receive either $1 \mathrm{~g}$ tranexamic acid $(\mathrm{n}=10,051)$ or placebo $(\mathrm{n}=10,009)$ in addition to standard care. A second dose of $1 \mathrm{~g}$ of tranexamic acid or placebo could be given if bleeding continued or restarted. Regarding the results, the WOMAN trial found that tranexamic acid decreased death due to bleeding [155 (1.5\%) vs $191(1.9 \%)$ ], especially in women given treatment within 3 hours of giving birth [89 (1.2\%) vs 127 (1.7\%), RR 0.69; 95\% CI 0.52 - 0.91; $\mathrm{p}=0.008$ ]. Laparotomy for bleeding was also reduced [82 (0.8\%) vs 127 (1.3\%), RR 0.64; $95 \%$ CI 0.49 - 0.85; $\mathrm{p}=0.002$ ] after caesarean section and vaginal delivery. The authors concluded: "tranexamic acid reduces death due to bleeding in women with postpartum hemorrhage with no adverse effects" [21]. ACOG also has recently updated its practice bulletin on postpartum hemorrhage, based on the results of The WOMAN trial. The researchers concluded that "Tranexamic acid reduces death due to bleeding in women with post-partum hemorrhage with no adverse effects. When used as a treatment for postpartum hemorrhage, tranexamic acid should be given as soon as possible after bleeding onset."

In 2012, WHO recommended use of tranexamic acid for the treatment of PPH if oxytocin and other uterotonics fail to stop the bleeding or if it is thought that the bleeding may be partly due to trauma [22]. WHO has recently updated their guidelines for use of tranexamic acid for treatment of postpartum hemorrhage: 
tranexamic acid should now be included in the treatment regimen for postpartum hemorrhage along with other drugs, irrespective of the cause of hemorrhage [23].

No previous clinical trials investigated the role of ethamsylate in either prophylaxis or treatment of postpartum hemorrhage. Our study was the first to use ethamsylate in obstetric practice giving it a pilot nature. A small number of patients are a point of weakness in our study.

\section{Conclusion}

Our results demonstrated that tranexamic acid and ethamsylate can be used safely to reduce bleeding during and after CS, and its use was not associated with any maternal and neonatal side effects. Tranexamic acid and ethamsylate appear to be a safe and effective option in the treatment of obstetric hemorrhage. In addition, the limited available evidence supports the need for a well-designed adequately powered clinical trial to test their benefit as a prophylactic agent.

\section{Authors' Contributions}

All authors had put the plan, collecting data, participate in the surgical procedure and follow up of the patients.

\section{Ethical Consideration}

Institutional review board (IRB) approval: The protocol was discussed by the ethical scientific committee of Ain Shams University Maternity Hospital.

\section{Subject Confidentiality}

All evaluation forms, reports, laboratory specimens, and other records that leave the site would not comprise unique personal data to maintain subject confidentiality.

\section{Consent Procedure}

The Investigator made a great concern that a correct informed consent process was in place to make sure that potential research subjects were fully addressed about the nature and objectives of this clinical trial, the potential hazards and gains of study participation, and also their rights as research subjects. The Investigator took the written, signed an informed consent from each participant before performing any study-specific technique on the participant. The investigator retained the forms of original signed informed consents.

All data and materials are available on request with agreement for publication.

\section{Acknowledgements}

Special thanks go to the patients and their families for the great support of our work. Also, the authors highly appreciate the support from Ain Shams University Maternity Hospital for the outstanding support during the entire experiment. 


\section{Conflicts of Interest}

The authors declare no conflicts of interest regarding the publication of this paper.

\section{References}

[1] Betrán, A.P., Merialdi, M., Lauer, J.A., Bing-Shun, W., Thomas, J., Van Look, P. and Wagner, M. (2007) Rates of 213 Caesarean Section: Analysis of Global, Regional and National Estimates. Paediatric and Perinatal Epidemiology, 21, 98-113. https://doi.org/10.1111/j.1365-3016.2007.00786.x

[2] Gibbons, L., Belizan, J.M., Lauer, J.A., Betran, A.P., Merialdi, M. and Althabe, F. (2012) Inequities in the Use of Cesarean Section Deliveries in the World. American Journal of Obstetrics \& Gynecology, 206, 331.E1-331.E19.

https://doi.org/10.1016/j.ajog.2012.02.026

[3] Magann, E.F., Evans, S., Hutchinson, M., Collins, R., Lanneau, G. and Morrison, J.C. (2005) Postpartum Hemorrhage after Cesarean Delivery: An Analysis of Risk Factors. Southern Medical Journal, 98, 681-685.

[4] Kramer, M.S., Berg, C., Abenhaim, H., Dahhou, M., Rouleau, J., Mehrabadi, A. and Joseph, K.S. (2013) Incidence, Risk Factors, and Temporal Trends in Severe Postpartum Hemorrhage. American Journal of Obstetrics \& Gynecology, 209, 449.E1-449.E7. https://doi.org/10.1016/j.ajog.2013.07.007

[5] Bateman, B.T., Berman, M.F., Riley, L.E. and Leffertlr, L.R. (2010) The Epidemiology of Postpartum Hemorrhage in a Large, Nationwide Sample of Deliveries. Anesthesia \& Analgesia, 110, 1368-1373. https://doi.org/10.1213/ANE.0b013e3181d74898

[6] Güngördük, K., Asicioglu, O., Celikkol, O., Olgac, Y. and Ark, C. (2010) Use of Additional Oxytocin to Reduce Blood Loss at Elective Caesarean Section: A Randomised Control Trial. Australian and New Zealand Journal of Obstetrics and Gynaecology, 50, 36-39. https://doi.org/10.1111/j.1479-828X.2009.01106.x

[7] National Institute for Health and Care Excellence. Caesarean Section. http://www.nice.org.uk/guidance/cg132

[8] Deneux-Tharaux, C., Sentilhes, L., Maillard, F., Closset, E., Vardon, D., Lepercq, J. and Goffinet, F. (2013) Effect of Routine Controlled Cord Traction as Part of the Active Management of the Third Stage of Labour on Postpartum Haemorrhage: Multicenter Randomised Controlled Trial (TRACOR). BMJ, 346, f1541. https://doi.org/10.1136/bmj.f1541

[9] Novikova, N. and Hofmeyr, G.J. (2015) Tranexamic Acid for Preventing Postpartum Haemorrhage. Cochrane Database of Systematic Reviews, No. 6, CD007872.

[10] Hellgren, M. (2003) Hemostasis during Normal Pregnancy and Puerperium. Seminars in Thrombosis and Hemostasis, 29, 125-130. https://doi.org/10.1055/s-2003-38897

[11] Charbit, B., Mandelbrot, L., Samain, E., Baron, G., Haddaoui, B., Keita, H., Sibony, O., Mahieu-Caputo, D., Hurtaud-Roux, M.F., Huisse, M.G., Denninger, M.H. and De Prost, D. (2007) PPH Study Group: The Decrease of Fibrinogen Is an Early Predictor of the Severity of Postpartum Hemorrhage. Journal of Thrombosis and Haemostasis, 5, 266-273. https://doi.org/10.1111/j.1538-7836.2007.02297.x

[12] Simonazzi, G., Bisulli, M., Saccone, G., Moro, E., Marshall, A. and Berghella, V. (2016) Tranexamic Acid for Preventing Postpartum Blood Loss after Cesarean Delivery: A Systematic Review and Meta-Analysis of Randomized Controlled Trials. 
Acta Obstetricia et Gynecologica Scandinavica, 95, 28-37. https://doi.org/10.1111/aogs.12798

[13] Li, C.B., Gong, Y.P., Dong, L.L., Xie, B.Y. and Dai, Z.Y. (2017) Is Prophylactic Tranexamic Acid Administration Effective and Safe for Postpartum Hemorrhage Prevention? A Systematic Review and Meta-Analysis. Medicine, 96, e5653. https://doi.org/10.1097/MD.0000000000005653

[14] Elbourne, D., Ayers, S., Dellagrammaticas, H., Johnson, A., Leloup, M. and Lenoir-Piat, S. (2001) Randomised Controlled Trial of Prophylactic Etamsylate: Follow up at 2 Years of Age. Archives of Disease in Childhood-Fetal and Neonatal Edition, 84, F183-F187. https://doi.org/10.1136/fn.84.3.F183

[15] Xu, J.J., Gao, W. and Ju, Y.N. (2013) Tranexamic Acid for the Prevention of Postpartum Hemorrhage after Cesarean Section: A Double-Blind Randomization Trial. Archives of Gynecology and Obstetrics, 287, 463-468.

https://doi.org/10.1007/s00404-012-2593-y

[16] Sekhavat, L., Tabatabaii, A., Dalili, M., Farajkhoda, T. and Tafti, A.D. (2009) Efficacy of Tranexamic Acid in Reducing Blood Loss after Cesarean Section. The Journal of Maternal-Fetal \& Neonatal Medicine, 22, 72-75. https://doi.org/10.1080/14767050802353580

[17] CRASH-2 Collaborators (2011) The Importance of Early Treatment with Tranexamic Acid in Bleeding Trauma Patients: An Exploratory Analysis of the CRASH-2 Randomized Controlled Trial. The Lancet, 377, 1096-1101. https://doi.org/10.1016/S0140-6736(11)60278-X

[18] Guerriero, C., Cairns, J., Perel, P., Shakur, H. and Roberts, I. (2011) Cost Effectiveness Analysis of Administering Tranexamic Acid to Bleeding Trauma Patients Using Evidence from the CRASH-2 Trial. PLoS ONE, 6, e18987. https://doi.org/10.1371/journal.pone.0018987

[19] Gai, M.Y., Wu, L.F., Su, .Q.F. and Tatsumoto, K. (2004) Clinical Observation of Blood Loss Reduced by Tranexamic Acid during and after Caesarian Section: A Multi-Center, Randomized Trial. The European Journal of Obstetrics \& Gynecology and Reproductive Biology, 112, 154-157. https://doi.org/10.1016/S0301-2115(03)00287-2

[20] Gungorduk, K., Yildirim, G., Asicioğlu, O., Gungorduk, O.C., Sudolmus, S. and Ark, C. (2011) Efficacy of Intravenous Tranexamic Acid in Reducing Blood Loss after Elective Cesarean Section: A Prospective, Randomized, Double-Blind, Placebo-Controlled Study. American Journal of Perinatology, 28, 233-240.

https://doi.org/10.1055/s-0030-1268238

[21] WOMAN Trial Collaborators (2017) Effect of Early Tranexamic Acid Administration on Mortality, Hysterectomy and Other Morbidities in Women with Post-Partum Haemorrhage (WOMAN): An International, Randomised, Double-Blind Blacebo-Controlled Trial. The Lancet, 389, 2105-2116. https://doi.org/10.1016/S0140-6736(17)30638-4

[22] World Health Organization (2012) WHO Recommendations for the Prevention and Treatment of Postpartum Haemorrhage. WHO, Geneva.

[23] World Health Organization (2017) Updated WHO Recommendation on Tranexamic Acid for the Treatment of Postpartum Haemorrhage. WHO, Geneva. Licence: CC BY-NC-SA 3.0 IGO. WHO/RHR/17.21 